\title{
Birds and Roads: Reduced Transit for Smaller Species over Roads within an Urban Environment
}

\author{
Christopher D. Johnson *, Daryl Evans and Darryl Jones \\ Environmental Futures Centre, Griffith University, Brisbane, QLD, Australia
}

Roads provide humans with a means of mobility between destinations, be it for transportation of goods and services or as a means of connecting with others. However, roads are also known to contribute toward a number of deleterious landscape processes, such as habitat destruction and fragmentation, pollution (e.g., chemical, noise and light) and animal mortality. Few studies however have investigated their effects on avifauna. We investigated the influence of road width on movements of nearby bird assemblages in Australia by comparing crossing counts of four species guilds and sizes over roads of varying widths in Southern Brisbane. In addition, we also sought to determine the association of seasonality with species crossing richness and abundance.

OPEN ACCESS

Edited by:

Clara Grilo,

Universidade Federal de Lavras, Brasil

Reviewed by:

Sandra L. Jacobson, United States Department of Agriculture Forest Service, USA Rafael Barrientos, Research Center in Biodiversity and Genetic Resources, Portugal Fernando Ascensão, CIBIO, Portugal

*Correspondence: Christopher D. Johnson christopher.johnson2@ uqconnect.edu.au

Specialty section: This article was submitted to Urban Ecology,

a section of the journal

Frontiers in Ecology and Evolution

Received: 09 November 2016 Accepted: 07 April 2017 Published: 02 May 2017

Citation:

Johnson $C D$, Evans $D$ and Jones $D$

(2017) Birds and Roads: Reduced Transit for Smaller Species over Roads within an Urban Environment. Front. Ecol. Evol. 5:36. doi: 10.3389/fevo.2017.00036 Species guild affiliations were based on definitions from previous literature: small forest dependent, large forest dependent, honeyeater, and urban tolerant; whereas body size classifications were arbitrarily defined: small $(<20 \mathrm{~cm})$, medium $(20-29 \mathrm{~cm})$, and large (>30 cm). Road sites were selected based on their vegetation likeness, both within and between sites, and this was assessed using the Specht classification system. We detected strong, negative correlations between road width and forest species richness, crossing species richness and species crossing abundance. In particular, analysis of species guild classifications revealed species richness and crossing likelihoods of the small forest dependent guild to be consistently lower than those of large forest dependent, honeyeater and urban tolerant guilds. Analysis of species by body size classification yielded similar outcomes: small birds were consistently less likely to be present nearby and cross over roads of all widths compared to medium and large birds. We believe gap permeability, particularly changes in vegetation structure and complexity that may restrict a species ability to access to the gap, as well as competition and predation, play an important role in determining species presence and crossing likelihood. Dense vegetation is known to benefit smaller species due to the provision of foraging resources and shelter from larger, more aggressive species.

Keywords: forest dependent, habitat fragmentation, road crossing, vegetation complexity, gap permeability, wildlife overpass, forest fragments, habitat connectivity

\section{INTRODUCTION}

Although people garner a number of benefits from roads, including transportation of goods and services and connectivity, roads exert a variety of negative effects on the surrounding environment: from changes in animal and vegetation communities (e.g., fragmentation) to altered geological processes (e.g., river hydrology and run-off) (Forman et al., 2003; Zhang et al., 2013; 
Morelli et al., 2014; Roberts and Sjolund, 2015; Selva et al., 2015) However, it is their ability to act as physical barriers to dispersal that has received considerable interest in the wider community, especially in instances where animals, particularly large mammals, attempt to navigate these barriers (Goosem and Marsh, 1997; Gleeson and Gleeson, 2012; Pell and Jones, 2015).

Despite their relative abundance, there have been few studies investigating the impacts of roads on birds, most likely due to the assumption that their ability to fly enables them to easily navigate fragmented landscapes and thus avoid the associated impacts (Lees and Peres, 2009; Kociolek et al., 2011; Jones and Pickvance, 2013; Kociolek et al., 2015). However, recent studies have demonstrated that birds, particularly forest dependent species, are quite susceptible to the effects of habitat fragmentation (Goosem and Marsh, 1997; Rytwinski and Fahrig, 2012; Jones and Pickvance, 2013; Evans, 2014; Pell and Jones, 2015). In fact, Lees and Peres (2009) noticed a significant number of Amazonian rainforest dependent species unwilling to cross gaps as narrow as $7 \mathrm{~m}$ in width, whereas Tremblay and St Clair (2009) found $45 \mathrm{~m}$ to be a significant threshold for dispersal.

This may be in part due to the absence of suitable habitat occurring along road verges due to road barrier and edge effects (Ford et al., 2000; Palomino and Carrascal, 2007; Evans, 2014). Habitat fragmentation is currently recognized as one of the greatest threats to species survival and is the result of sub-dividing one area of continuous habitat into smaller, separate "fragments" (Ford et al., 2000; Benitez-Lopez et al., 2010; Campbell et al., 2010; Evans, 2014). This is of particular concern as remaining habitat fragments, particularly fragment edges, become susceptible to continued disturbance through changes in abiotic (light, rainfall, resource availability, etc.) and biotic (e.g., predator-prey interaction) factors (Benitez-Lopez et al., 2010; Evans, 2014). The end result is a fragment encompassed by an "edge" that is typically intermediate in complexity to that of the fragment core and the disturbed landscape (Ford et al., 2000; Forman et al., 2003; Campbell et al., 2010; Evans, 2014). As a result, many remaining species become significantly more susceptible to population level effects (e.g., genetic drift and resource availability) as fragments become smaller and more isolated from one another (Lees and Peres, 2009; Campbell et al., 2010; Zimmer and Emlen, 2013; Zhang et al., 2013; Evans, 2014).

Traffic volume has also been shown to negatively correlate with reductions in species density and breeding (Reijnen and Foppen, 2006). Specifically, birds exposed to loud noise experienced elevated stress levels, such as increased heart rate, which over time may translate into increased risk of developing physiological stress and/or physiological disorders. Traffic noise has also been shown to interfere with bird songs, which are used in attracting mates and establishing and defending territories (Kociolek et al., 2011; Jack et al., 2015). In particular, species that utilize songs at lower frequencies were typically more adversely affected by traffic noise than those utilizing higher frequencies, leading to a net deficit of those species along road edges (St Claire, 2003; Kociolek et al., 2011).

Life history traits may also help to explain the disparities in species dispersive capabilities. Pell and Jones (2015) noticed that smaller birds, especially those dependent on forest vegetation for cover, typically displayed wide wings in proportion to their overall body size; a trait that is known to assist with short, acrobatic flight amongst dense vegetation and thus may not be suitable for extended flight (Norberg, 1989; Keast, 1996). However, not all data currently available on road crossing likelihood can be explained solely by differences in species wing morphology. According to Lees and Peres (2009), highly mobile species appear to be largely unaffected by gap distances between forest patches compared to less mobile species; the latter were rarely observed to cross wide clearings. Larger bodied birds have also been observed to cross more frequently than lighter bodied birds (Lees and Peres, 2009; Rytwinski and Fahrig, 2012). Home range also appears to be closely correlated with crossing likelihood: species present over a wider area, and thus more habitat patches, are more willing to move between forest patches than species that were more range/habitat restricted. Finally, flocking tendency in birds was found to restrict patch movement with gregarious species being much less likely to cross compared to solitary species (Lees and Peres, 2009).

In contrast, there is some evidence to suggest that some birds may benefit from roads: power-lines, signs and roadside vegetation may serve as useful ecological corridors through the provision of suitable nesting, refuge and perching habitats (Morelli et al., 2014). Road surfaces and verges may also act as potential foraging and scavenging sites and may even aid species in energy conservation (i.e., core body temperature) (Laurance, 2015). The provision of roadside lighting may also extend foraging time and activities of both diurnal species, being able to forage for longer hours each day, and nocturnal species, using the lights to hunt for congregating prey items (Morelli et al., 2014). However, only certain species appear to benefit from such structures; these include raptors and other scavenging species, urban adapted, introduced and woodland species (Morelli et al., 2014). For other taxa, it is suggested that these same features further amplify the effect of road mortality through collisions with vehicles (Orlowski, 2008; Benitez-Lopez et al., 2010; Kociolek et al., 2011; Jack et al., 2015).

Nevertheless, birds form part of an intricate web within the environment, providing and maintaining numerous ecosystem services that humans are dependent on for sustained growth and prosperity (Whelen et al., 2008; Campbell et al., 2010). For example, birds are important predators of agriculturally important pest species (Whelen et al., 2008; Philpott et al., 2009), pollinators and dispersers of medically and economically important plant species (Wenny et al., 2011) and ecosystem mediators (Anderson, 2003). This is of particular concern in urbanizing areas where habitat destruction and roads increasingly fragment the landscape. In southeast Queensland, Australia, for example, $\sim 273$ species (30\% of all Australian species) are currently distributed across the highly urbanized Bulimba Creek catchment, nearly $50 \%$ of which occur in three or fewer isolated populations (Evans, 2014). Moreover, the demand for more and better roads continues to rise as the number of people living and working within southeast Queensland increases, which will in turn further fragment animal populations in an already highly urbanized landscape (Jones et al., 2011; Zhang et al., 2013; Evans, 2014; Jones et al., 2014; Jack et al., 2015). 
It is therefore important to better understand the relationship between birds and roads in Southeast Queensland so that susceptible species can be identified and appropriate corrective measures or mitigating strategies can be incorporated into future planning.

The overall aim of this study was to investigate the relationship between road width and the associated probability of birds crossing them in Southern Brisbane. Specifically, this paper attempted to address the following questions:

(A) Do roads of different widths influence forest species presence adjacent to roads in Southern Brisbane?

(B) Does road width influence species crossing preferences based on guild and body size classifications?

(C) Does roadside species composition differ to forest species composition based on guild and body size classifications?

It is hoped that the findings will further improve upon current knowledge and understanding of fauna movements and roads as well as highlight the need for funding for artificial animal crossings to help circumvent road crossing mortality rates and maintain populations within a fragmented landscape.

\section{METHODOLOGY}

This study took place within the southern suburbs of Brisbane, a city of approximately two million people located in coastal southeast Queensland, Australia. Monitoring was undertaken in 12 study sites along roads of varying width: four small $(15 \mathrm{~m})$, four medium $(\sim 40 \mathrm{~m})$, and four large $(\sim 75 \mathrm{~m})$, each comparable to one to two-lane, four-lane and six-lane carriageways, respectively. Each section examined was $30 \mathrm{~m}$ in length and this was to ensure accurate identification of crossing species. Study sites were selected based on vegetation likeness, that is, roads with similar vegetation on both sides, as it was assumed that bird crossings were more likely to occur between similar habitats than dissimilar habitats. It should be noted that the terminology of a road gap within this paper refers to the widths of the sealed surface as defined as small $(15 \mathrm{~m})$, medium $(\sim 40 \mathrm{~m})$ or large $(\sim 75 \mathrm{~m})$. GPS coordinates of all survey sites were recorded using a Garmin eTrex Venture personal navigator and were accurate to within 11 meters.

\section{Site Descriptions and Vegetation Assessment}

For the purposes of this investigation, vegetation structure and composition of forest sites were classified using the standardized Specht "Vegetation Classification by Structure" (Specht, 1970; Australian National Botanic Gardens, 2014). For site details, see Appendix 1 in Supplementary Material.

\section{Bird Crossing Surveys}

Overall, the monitoring method was adapted from that of a similar, previously conducted study (Pell and Jones, 2015). Three surveys were conducted at each road site; one road survey and two forest surveys.

Road surveys were conducted by a single observer along the road edge at each site over a 20 -min period. Prior to the commencement of the study, a $30 \mathrm{~m}$ wide count area was established, using marking tape, at each of the road sites. From the edge, the observer was then stationed in the middle of each count area and recorded any birds that successfully flew across the road. For the purposes of this study, a successful crossing was defined as an event in which the individual(s) traveled from one side of the road to the other, either landing within the roadside vegetation or continue through. Individuals observed to either enter or exit the count area during their fly-over were also recorded as having successfully crossed. For example, a bird was recorded as having crossed if it entered the count area but exited away from and outside of the count area on the opposite side and vice versa. Individuals that either crossed away from the count area or did not cross to the opposite side (i.e., they returned or flew along the road) were not recorded as having completed a successful crossing.

Forest surveys were conducted in tandem to the road surveys. For the purposes of this study, forested sites surveyed within urban areas were a minimum of 30 ha in size and contiguous with surrounding forest fragments via a wildlife corridor network. During these, the observer would stand at a point within the roadside vegetation, $\sim 100 \mathrm{~m}$ in from the road edge, and record all new observations and vocalizations over a $20 \mathrm{~min}$ period. It should be noted that a species did not necessarily need to be sighted in order to be recorded as being present within the forest survey site. All records were identified to the species if possible through the use of the field guide Morcombe (2004). Two forest surveys were conducted at each site on opposite sides of the roads.

The first site survey began $\sim 30$ min after sunrise. A maximum of three road sites were surveyed each morning, with a total of nine surveys completed between 06:30 and 10:00 during the spring 2015 period (September-November 2015) and 5:30 and 9:30 during the summer 2015/2016 period (DecemberFebruary). All 15 study sites were surveyed four times each during spring (September-November 2015) and four times each during summer (2015 December-February 2016). Data obtained from road and forest surveys were later combined to create a master species list specific to each road site.

All necessary permissions were obtained and the appropriate authorities notified prior to beginning all road survey work. At no point did the observer enter the road, other than to cross from one side to the other to reach the next survey site and only if and when safe to do so. Permissions were also sought prior to accessing and conducting survey work on private property.

\section{Species Classifications}

Species guild classifications were based on Pell and Jones (2015) and were as follows:

- Urban tolerant-species that are generalist species capable of colonizing and persisting within a range of different environments, although are typically associated with humans and related activities.

- Honeyeater-small to medium sized birds typically reliant on flowering trees for food and may travel great distances in search of blooms. 
- Large forest dependent-birds $>40 \mathrm{~g}$ in weight and are generally found within forest and woodland. Diets are speciesspecific, but commonly consist of insects (insectivores), seeds (granivores) and fruit (frugivores), although some larger species may incorporate small animals into their diets (omnivores).

- Small forest dependent-birds $<40$ g in weight and are typically reliant on forest vegetation. Diets tend to consist of small insects, seeds and fruit.

Species body size was also investigated and analyzed in tandem with species guild classifications. Body size was investigated as an alternative to species guilds: previous literature has focussed primarily on investigating the relationship between species life histories (i.e., guilds) and level of susceptibility to road barrier effects. Species body size classifications are as follows:

- Small: birds $<20 \mathrm{~cm}$ in length,

- Medium: birds 20-29 cm in length,

- Large: birds $\leq 30 \mathrm{~cm}$ in length.

\section{Statistical Analysis}

The numbers of species and species types present, species and individuals crossing and crossing times were recorded. Count gathered data were used to calculate rates of crossing and probabilities at the species guild and body size levels. Particular emphasis was placed on differences in species presence at forest and road crossing sites, as well as numbers of crossing individuals of species of different guilds and body sizes. The outcomes of species guild and species size richness, crossing counts across the three road gap categories (small, medium and large) were analyzed using negative binomial regression. The relationship between forest species richness and road crossing counts was examined using bivariate correlation. The degrees of similarity between study sites during and between spring and summer were assessed by lower triangular resemblance matrices, using Sorensen Index of Similarity (Dice Indicies), and Multi-Dimensional Ordnance. All statistical analyses were conducted using IBM Statistical Package for the Social Sciences (SPSS) Statistics software (Version 22.0. Armonk, NY: IBM Corporation) and STATA (version 14.0, College Station, TX: StataCorp LP, USA). $P<0.05$ were considered statistically significant.

\section{RESULTS}

Surveys of species forest and road gap richness at small, medium and large roads were undertaken between spring 2015 (September-November) and Summer 2015/2016 (DecemberFebruary). In total, 88 species were recorded at forest survey sites during the 6-month observation period: 24 small forest dependent, 24 large forest dependent, 11 honeyeater and 29 urban tolerant. A total of 770 birds (from 51 species) were observed to cross roads during the 6-month observation period: 88 small forest dependent (from 10 species), 129 large forest dependent (from 9 species), 117 honeyeater (from 11 species), and 376 urban tolerant (from 21 species).

\section{Site Vegetation}

Similar vegetation was observed across all 15 study sites and was consistent with the Specht description of open forest: projective cover of the tallest stratum between 30 and $70 \%$ and tallest stratum between 10 and $30 \mathrm{~m}$ (Appendix 2 in Supplementary Material). Although canopy stratum remained similar across the study sites, differences in structure and composition of the understorey layers were observed: understorey cover was visibly denser adjacent to small gaps, whereas this was largely diminished nearby large gaps.

\section{Birds Present at Forest Sites}

Compared with small roads, no significant difference was observed in forest species richness for either medium roads (incidence rate ratio [IRR] 1.08, 95\% confidence interval [CI] $0.91-1.28, p=0.41$ ) or large roads (IRR 0.88, 95\% CI 0.74-1.06, $p=0.18$ ) (overall $p=0.10$ ). However, when spring counts were analyzed separately, forest species richness near large roads was significantly lower than both small roads (IRR 0.73, 95\% CI 0.57$0.95, p=0.02$ ) and medium roads (IRR $0.75,95 \%$ CI $0.58-0.97$, $p=0.03$ ). For summer, no differences were observed in forest species richness between small, medium and large roads (overall $p=0.37)$.

\section{Species Guilds and Forest Species Richness}

Following adjustment for species guilds, forest species richness adjacent to large roads tended to be lower than that adjacent to small roads (IRR $0.88,95 \%$ CI $0.74-1.06, p=0.17$ ) and was significantly lower than that adjacent to medium roads (IRR 0.82, 95\% CI $0.69-0.98, p=0.03$ ) (Table 1). The reduction in forest species richness adjacent to large roads was significantly more apparent during spring (small roads reference; medium roads IRR $0.98,95 \%$ CI $0.98,95 \%$ CI $0.77-1.24, p=0.86$; large roads IRR $0.74,95 \%$ CI $0.57-0.95, p=0.02$ ) (overall $p=0.04$ ). Forest species richness adjacent to large roads was also significantly lower than that for medium roads (IRR 0.76, 95\% CI 0.58-0.98, $p=0.03)$. No such differences were observed during summer (overall $p=0.32$ ).

Compared with the small forest dependent guild, species crossing richness was significantly lower for both the large forest dependent guild (IRR 0.74, 95\% CI 0.6-0.92, $p=0.01$ ) and the honeyeater guild (IRR $0.66,95 \%$ CI $0.53-0.82, p<0.01$ ), but higher for the urban tolerant guild (IRR1 0.50, 95\% CI 1.25$80, p<0.01$ ) (overall $p<0.001$ ). Similar findings were apparent

\begin{tabular}{|c|c|c|c|c|}
\hline $\begin{array}{l}\text { Road } \\
\text { width }\end{array}$ & $\begin{array}{l}\text { Small forest } \\
\text { dependent }\end{array}$ & $\begin{array}{l}\text { Large forest } \\
\text { dependent }\end{array}$ & Honeyeater & $\begin{array}{l}\text { Urban } \\
\text { tolerant }\end{array}$ \\
\hline Small & 20 & 18 & 9 & 23 \\
\hline Medium & 23 & 18 & 10 & 23 \\
\hline Large* $^{*}$ & 19 & 15 & 8 & 24 \\
\hline
\end{tabular}

${ }^{*}$ Denotes significantly different result from either one or both other road width types within the same species category. 
during both spring (small forest dependent reference; large forest dependent IRR $0.67,95 \%$ CI $0.49-0.91, p=0.01$; honeyeater IRR $0.69,95 \%$ CI $0.50-0.94, p=0.02$; urban tolerant IRR $1.43,95 \%$ CI $1.11-1.9, p=0.006$ ) (overall $p<0.01$ ) and summer (small forest dependent reference; large forest dependent IRR 0.82, 95\% CI $0.61-1.12, p=0.19$; honeyeater IRR 0.63 , 95\% CI $0.45-0.87$, $p=0.01$; urban tolerant IRR $1.56,95 \%$ CI 1.21-2.03, $p<0.01$ ) (overall $p<0.01$ ).

\section{Species Body Size and Forest Species Richness}

Following adjustment for species body size, forest species richness adjacent to large roads tended to be lower than that adjacent to small roads (IRR $0.88,95 \%$ CI $0.74-1.06, p=0.18$ ) and was significantly lower than that adjacent to medium roads (IRR $0.82,95 \%$ CI $0.70-0.98, p=0.03$ ) (Table 2). The reduction in forest species richness adjacent to large roads was significantly more apparent during spring (small roads reference; medium roads IRR 0.94, 95\% CI 0.77-1.24, $p=0.856$; large roads IRR 0.73, $95 \%$ CI $0.57-0.95, p=0.02$ ) (overall $p=0.03$ ). Forest species richness adjacent to large roads was also significantly lower than that for medium roads (IRR $0.75,95 \%$ CI $0.58-0.97, p=0.03$ ). No such differences were observed during summer (overall $p=0.37$ ).

No differences were observed between different body size groups (overall $p=0.33$ ).

\section{Which Birds Crossed Roads? Road Crossing Species Richness}

Large roads were associated with significantly lower species crossing richness compared with both small roads (IRR 0.45, 95\% CI $0.29-0.70, p<0.01$ ) and medium roads (IRR 0.40, 95\% CI $0.25-0.61, p<0.01$ ) (overall $p<0.001$ ). The reduction in crossing richness was similarly apparent during both spring (small roads reference; medium roads IRR 1.07 , 95\% CI $0.68-$ $1.69, p=0.761$; large roads IRR $0.39,95 \%$ CI $0.21-0.71, p<0.01$ ) (overall $p=0.002$ ). and summer (small roads reference; medium roads IRR $1.2,95 \%$ CI $0.67-2.14, p=0.54$; large roads IRR 0.51 , $95 \%$ CI $0.26-1.01, p=0.05$ ) (overall $p=0.04$ ). Equivalent results were observed even after multivariable adjustment for species guild and body size (Tables 1, 2).

\section{Species guild}

Following adjustment for road size, road crossing species richness also differed significantly between species guilds (overall $p<0.0001$ ) (Table 3). Compared with the small forest dependent guild, crossing species was higher for all other guilds (large forest dependent IRR 1.62, 95\% CI 0.99-2.63, $p=0.06$; honeyeater

TABLE 2 | Overall species richness at forest sites arranged by body size.

\begin{tabular}{lccc}
\hline Road width & Small bird & Medium bird & Large bird \\
\hline Small & 17 & 13 & 20 \\
Medium & 21 & 14 & 20 \\
Large $^{\star}$ & 16 & 11 & 19 \\
\hline
\end{tabular}

${ }^{*}$ Denotes significantly different result from either one or both other road width types within the same species category.
IRR 1.69, 95\% CI 1.04-2.75, $p=0.03$; urban tolerant IRR 3.31, 95\% CI 2.13-5.13, $p<0.0001)$. Similar patterns were observed during both spring (overall $p=0.005)$ and summer $(p<0.001)$. Sorenson Index of Similarity revealed relatively uniform species distributions at all study sites during spring and summer.

\section{Pecies body size}

Following adjustment for road size, road crossing species richness was significantly greater for both medium birds (IRR 2.02,95\% CI 1.37-2.97, $p<0.001$ ) and large birds (IRR 1.58, 95\% CI 1.06-2.37, $p=0.03$ ) compared with small birds (overall $p=0.002$ ) (Table 4). Although a similar pattern was observed during summer (overall $p<0.001$ ), no significant differences were observed between small, medium and large birds during spring (overall $p=0.39$ ).

\section{Numbers of Birds Crossing Roads}

Overall, large roads were associated with significantly lower road crossing counts compared with medium roads (IRR 0.47, 95\% CI $0.25-0.88, p=0.02$ ) and tended to be associated with lower counts compared to small roads (IRR $0.60,95 \%$ CI $0.32-1.12, p$ $=0.11$ ) (overall $p=0.05$ ). Similar results were observed during spring (overall $p=0.03$ ), although no differences were observed between road sizes during summer (overall $p=0.55$ ).

\section{Species guilds and numbers of birds crossing roads}

Following adjustment for species guilds, overall roadcrossing counts were not significantly different between

TABLE 3 | Total number of species observed to cross roads arranged by guild membership.

\begin{tabular}{lccccccc}
\hline Species category & \multicolumn{5}{c}{ Road width } \\
\cline { 2 - 6 } & \multicolumn{3}{c}{ Spring } & & \multicolumn{3}{c}{ Summer } \\
\cline { 2 - 6 } \cline { 5 - 7 } & Small & Medium & Large* & Small & Medium & Large* \\
\hline Small forest dependent* & 5 & 2 & 0 & 5 & 5 & 1 \\
Large forest dependent & 4 & 7 & 4 & 6 & 5 & 2 \\
Honeyeater & 8 & 8 & 1 & 5 & 7 & 2 \\
Urban tolerant & 8 & 14 & 6 & 8 & 10 & 7 \\
Total & 25 & 31 & $11^{*}$ & 24 & 27 & $12^{\star}$
\end{tabular}

*Denotes significantly different result from either one or both other road width types within the same species category.

TABLE 4 | Total species observed to cross roads arranged by body size.

\begin{tabular}{|c|c|c|c|c|c|c|}
\hline \multirow[t]{3}{*}{ Body size } & \multicolumn{6}{|c|}{ Road width } \\
\hline & \multicolumn{3}{|c|}{ Spring } & \multicolumn{3}{|c|}{ Summer } \\
\hline & Small & Medium & Large & Small & Medium & Large* \\
\hline Small* & 9 & 6 & 0 & 7 & 7 & 1 \\
\hline Medium & 7 & 12 & 5 & 12 & 12 & 4 \\
\hline Large & 9 & 13 & 6 & 5 & 8 & 7 \\
\hline Total species crossed & 25 & 31 & $11^{*}$ & 24 & 27 & $12^{*}$ \\
\hline
\end{tabular}

${ }^{\star}$ Denotes significantly different result from either one or both other road width types within the same species category. 
different road sizes (overall $p=0.14$ ) and during spring $(p=0.12)$.

However, a significant difference was found between different guilds (overall $p<0.001$ ) in that the urban tolerant guild had significantly higher crossing counts than the small forest dependent guild (IRR 3.07, 95\% CI 1.73-5.47, $p<0.001$ ). A similar pattern was observed during summer (overall $p<0.001$ ), but not during spring (overall $p=0.21$ ).

\section{Species body size and numbers of birds crossing roads}

Following adjustment for body size, large roads were associated with significantly lower road crossing counts compared with both medium roads (IRR $0.45,95 \%$ CI $0.26-0.79, p=0.005$ ) and small roads (IRR $0.41,95 \%$ CI $0.22-0.75, p=0.004$ ) (overall $p=0.005$ ). Similar results were observed during spring (overall $p=0.007$ ), although no differences were observed between road sizes during summer (overall $p=0.22$ ).

Compared with small birds, medium birds crossed roads more frequently (IRR 3.48, 95\% CI 1.93-6.27, $p<0.001$ ), although large birds did not (IRR 1.44, 95\% CI 0.79-2.62, $p=0.23$ ) (overall $p<0.001)$. Similar results were observed during both spring (overall $p=0.008)$ and summer $(p=0.006)$.

\section{How Many Forest Bird Species Crossed Roads?}

During both survey periods, a total of 88 species was recorded at forest survey sites, 51 (58\%) of which were observed to undertake successful road crossings (Table 5). A moderately strong positive correlation was observed between forest species richness and road crossing species richness $(r=0.43, p<0.0001)$.

\section{DISCUSSION}

\section{Key Findings}

The primary objective of this investigation was to examine the road crossing likelihoods of birds present in Southern Brisbane in the context of growing levels of habitat fragmentation and

TABLE 5 | Number of species in each guild detected at forest sites over the duration of the study.

\begin{tabular}{llcc}
\hline & Species guild & Forest richness & Crossed roads \\
\hline Total & Small forest dependent & 24 & 10 \\
& Large forest dependent & 24 & 11 \\
& Honeyeater & 11 & 9 \\
& Urban tolerant & 29 & 21 \\
\hline \multirow{2}{*}{ Spring 2015 } & Small forest dependent & 22 & 6 \\
& Large forest dependent & 21 & 8 \\
& Honeyeater & 9 & 17 \\
& Urban tolerant & 26 & 7 \\
\hline \multirow{2}{*}{ Summer 2015/2016 } & Small forest dependent & 23 & 9 \\
& Large forest dependent & 19 & 7 \\
& Honeyeater & 10 & 15
\end{tabular}

urbanization. Despite the significance of these issues, as well as strong interest within the wider community, few studies have investigated gap-crossing abilities of these species. Those that have taken place have occurred in very different regions and outside of urban settings (St Claire, 2003; Lees and Peres, 2009; Benitez-Lopez et al., 2010; Kociolek et al., 2011).

The present study demonstrated that large roads were independently associated with reduced bird crossing counts and species cross richness compared with medium and small roads. Subsequently, these findings were further enhanced when adjusting for the influence of species guilds and species body size. Although it was hypothesized that all four species guilds would be similarly affected by road width, the present study revealed the small forest dependent guild to be the most prone: species richness at forest sites and crossing over road sites (i.e., number of species crossing) was consistently lower compared to the large forest dependent, honeyeater and urban tolerant guilds. This finding was partly consistent with a number of previous studies (St Claire, 2003; Reijnen and Foppen, 2006; Lees and Peres, 2009; Kociolek et al., 2011; Pell and Jones, 2015) and was further reinforced by the analysis of species body size, which revealed that "small" $(<20 \mathrm{~cm})$ birds were consistently less likely to cross roads compared to medium $(20-29 \mathrm{~cm})$ and large birds $(>30 \mathrm{~cm})$.

Similar observations were also made in one other prior study (Pell and Jones, 2015) examining the relationship between urban roads and bird crossings in Australia. Specifically, Pell and Jones (2015) observed reductions in species richness and numbers of birds crossing over roads, especially those of small forest dependent species. Pell and Jones (2015) also noted several species unwilling to cross directly over a main road, instead crossing via a nearby vegetated fauna overpass. However, the primary focus of their study was to assess the conservation value of fauna overpasses in movement solutions. The present study builds on the findings by Pell and Jones (2015) by (a) providing statistically more powerful and generalizable results with respect to bird-gap crossings (12 sites across the southern Brisbane region vs. 4 sites near Karawatha Forest, respectively); (b) accounting for seasonal variation in species movements; and (c) comparing and contrasting the influence of both individual size and species guild classification on species road gap crossing likelihood.

\section{Habitat Augmentation}

Previous studies have highlighted the importance of the road barrier effect in determining the distributions of numerous fauna and flora species near roads and related structures (Forman et al., 2003; Morelli et al., 2014; Van der Ree et al., 2015). Birds have been identified as being highly susceptible to road barrier effects despite their ability to fly (Morelli et al., 2014), with fewer species being present near roads, a finding reflected in the results of the current study.

Roadside vegetation, particularly the understory, was observed to diminish with increasing road width and this coincided with reductions in both species forest richness and road crossing likelihood, especially those of smaller species. In particular, wider roads (e.g., Logan and Pacific 
Motorways) appeared more highly disturbed, with visibly sparser vegetation and wide maintained grass "shoulders"; whereas small roads (e.g., Hemmant-Tingalpa Road, Pine Mountain Road) appeared to be more "intact," with denser vegetation nearer to the road. Importantly, numerous studies have reported similar associations between crossing likelihood and vegetation structure (Erickson et al., 2005; Orlowski, 2008; Lees and Peres, 2009; Thinh et al., 2012; Jones and Pickvance, 2013; Laurance, 2015).

Habitat destruction and fragmentation often result following the construction of roads, which in turn lead to altered environment conditions (often negative) in the surrounding landscape (Ford et al., 2000; Kociolek et al., 2011; Amos et al., 2014). This is believed to directly impact upon nearby populations of small forest dependent birds due to their heavy reliance on resources supplied by the dense understory and mid-story vegetation layers (i.e., food, shelter and nesting sites) (Desrochers and Hannon, 1997; Ford et al., 2000; Kutt and Woinarski, 2007; Tremblay and St Clair, 2009; Jones and Bond, 2010; Jones et al., 2011; Thinh et al., 2012; Laurance, 2015). Indeed, Kutt and Martin (2010) observed foraging height to accurately predict species responses to changing native vegetation structure and complexity in north Australian savannah woodlands. Specifically, small insectivores (e.g., rufous whistler, Pachycephala rufiventris; gray fantail, Rhipidura fuliginosa; and variegated fairy-wren, Malurus lamberti) were found to be most susceptible to changes in forest structure and complexity, whereas species foraging within the upper strata, such as honeyeaters (e.g., noisy friarbird, Philemon corniculatus; and little friarbird, Philemon citrogularis) and large insectivores (e.g., black-faced cuckoo-shrike, Coracina novaehollandiae; and gray butcherbird, Cracticus torquatus), were less susceptible (Kutt and Martin, 2010). This is significant as many forests within Brisbane, specifically public bushland and reserves adjacent to built-up areas, are exposed to multiple maintenance regimens, including fire, mowing and spraying.

This may further exacerbate the deleterious influence of roads for a number of nearby populations through the establishment of highly competitive edge specialist species capable of utilizing the new resources provisioned by roads (Grarock et al., 2014; Morelli et al., 2014). For example, a number of highly aggressive species, including the noisy miner (Manorina melanocephala), blue-faced honeyeater (Entomyzon cyanotis) and noisy friarbird (Philemon corniculatus), were regularly observed at a number of more highly disturbed sites in the current study (personal observation). Previous studies have observed sharp declines in the richness of smaller birds, including other honeyeaters, in resource scarce areas where they were present at moderate numbers (Ford et al., 2000; Oldland et al., 2009; Kutt et al., 2011; Montague-Drake et al., 2011). Furthermore, gaps in vegetation may also serve as territory boundaries for a number of edge specialist species that may further restrict the homerange gap crossings of conspecifics (Lees and Peres, 2009). For example, in the present study, several sacred kingfisher (Todiramphus sanctus) pairs were recorded near small roads and associated structures but were rarely observed to cross
(CJ personal observation). On the few occasions that this happened, brief but aggressive fights ensued (CJ personal observation).

Similarly, small birds are highly susceptible to predation outside of cover: observations of many large predatory species within this study appeared to coincide with visible reductions in species movements and activities, particularly those of smaller birds, a finding consistent with those of previous studies (Desrochers and Hannon, 1997; Orlowski, 2008; Lees and Peres, 2009). Moreover, Jacobson et al. (2016) proposed a species susceptibility to road barrier effects to be related to their ability to recognize and respond to potential predators and threats. "Nonresponders" failed to recognize the threat and crossed irrespective of traffic conditions; "Pausers" stopped in the face of danger; "Speeders" fled in the face of danger; while "Avoiders" were able to recognize traffic as potential predators and began to avoid roads at lower traffic volumes. Within the current study, small forest dependent species were more often observed within forest sites nearby roads, with noticeably few observed to cross. On the other hand, large forest dependent, honeyeater and urban tolerant species appeared less deterred by road gap width.

\section{Species Morphology}

Both Lees and Peres (2009) and Jones and Pickvance (2013) noted that disproportionate numbers of larger bodied species crossed open gaps in vegetation between fragments, whereas smaller bodied species appeared to prefer vegetated corridors when crossing. This may reflect differences in species life histories (Rytwinski and Fahrig, 2012). For example, Keast (1996) found wing-shape to vary significantly with species habitat preferences. Specifically, small rainforest species possessed wider and rounded wings, a configuration suited to maneuvering amongst dense vegetation (e.g., understory) and capturing insects, whereas larger eucalypt woodland species possessed long and narrow wings for strong and extended flight over distances (Norberg, 1989; Keast, 1996). This may therefore mean that small forest dependent species in general are ill equipped to cross larger roads, as observed in this study. However, it should also be noted that this wing-body morphology is also expressed in some larger species, such as the pheasant coucal and brushturkey, both of which exhibited similar trends in crossing likelihood.

\section{Traffic}

Habitat degradation is known to reduce the surrounding landscape's ability to buffer against noise pollution, particularly within forested regions (Reijnen and Foppen, 2006; BenitezLopez et al., 2010). Previous studies have shown several species to experience elevated levels of stress, including elevated heart rate and hypervigilance (i.e., predator awareness), following short-term exposure to loud noises associated with high vehicle volume roads, prompting many to retreat to quieter areas further away (St Claire, 2003; Reijnen and Foppen, 2006). Helb and Hupop (in Reijnen and Foppen, 2006) suggest that repeated long-term exposure to such noise levels may increase risk of physiological and psychological stress and disorders. 
Artificial noise, such as that produced by traffic, may also mask bird calls of similar frequencies (Rheindt, 2003; Goodwin and Shriver, 2010; Francis et al., 2011). This is especially important as birds, particularly passerines, use calls in communication, territory defense and courtship (St Claire, 2003; Reijnen and Foppen, 2006; Read et al., 2015). In a recent study, Read et al. (2015) observed disturbance responses of 89 Australian species at varying distances from a nearby mine (Olympic Dam Mine) for potential use as indicators of environmental health. Unsurprisingly, fewer species were present at sites nearer the mine compared to sites situated further away, which the authors attributed to masking by noise produced by the mine (Read et al., 2015). However, acoustic masking is thought to primarily affect species utilizing low pitch calls, a trait typically associated with larger-bodied birds. This may in part explain why fewer observations were made in forests nearer wider, high traffic roads for some large forest dependent and urban tolerant species (e.g., gray shrike-thrush, Colluricincla harmonica; pheasant coucal, Centropus phasianinus; eastern koel, Eudynamys scolopacea; pied butcherbird, Cracticus nigrogularis; and willie wagtail, Rhipidura leucaphrys). However, it should be noted that although previous studies have identified negative correlations between traffic noise and species richness and abundance, traffic noise was not the dominant cause for the declines (Summers et al., 2011).

\section{Seasonal Variation: Forest Richness and Road Crossings}

The findings of this study suggested modest seasonal fluctuations in species abundance. Species richness across the forest sites appeared to become more uniform during summer. Similarly, numbers of species observed to cross increased slightly during summer. Sorenson's Index of Similarity also revealed slight increases in species compositions at forest sites and crossing roads during summer.

It is quite possible that these observed patterns may relate to seasonal variations in resource availability. According to Reside et al. (2010), rainfall within Australia is highly seasonal due to strongly variable inter-annual weather patterns, which in turn influences the abundances of flowering plants and insects. As a result, a number of species, most notably the honeyeaters, have evolved high vagility in order to track these episodic resource booms (Griffioen and Clarke, 2002; Reside et al., 2010). In particular, noticeably fewer observations of a number of species, such as scarlet honeyeater, brown honeyeater, whitethroated treecreeper, mistletoebird, and gray fantail, appeared to coincide with lower perceived rainfall frequency and bloom intensity at forest sites during summer (CJ personal observation). However, this explanation does not support the observed increase in species forest and road compositions between seasons, possibly due to greater richness of a number of species normally considered sedentary (Griffioen and Clarke, 2002).

Alternatively, seasonal patterns in the data may be more accurately explained through species reproductive behaviors and strategies of both adult and juvenile birds (Desrochers and
Hannon, 1997). In particular, many species recorded at forest sites were observed to be undertaking a number of breeding activities, including courtship and territorial displays, nest construction and food gathering during spring. Subsequently, sightings of juvenile birds at forest and road sites became more frequent during summer (personal observation). Importantly, the timing of these activities and movements, particularly those of the gray fantail and noisy miner, are consistent with observations previously reported by Griffioen and Clarke (2002) and Ford et al. (2000).

\section{CONCLUSIONS AND IMPLICATIONS}

This study, to the knowledge of the authors, is the first in Australia to have investigated, assessed and evaluated the impact of roads on bird richness and crossings. Its key findings were that both forest species richness and numbers of road crossing species declined significantly with increasing road width and that these negative effects were most obvious for the small forest dependent guild compared to large forest dependent, honeyeater and urban tolerant guilds. Moreover, numbers of road crossing individuals also declined significantly with road gap width and were most obvious in small birds $(<20 \mathrm{~cm})$. Finally, species compositional similarities at both forest and road sites increased slightly between spring and summer, suggesting some seasonal variation to be present within the data. These findings are of value to the understanding of both conservation and the ecological role of birds in ecosystem health and functioning through the provision of a number of beneficial services, such as pollination, seed dispersal and arthropod control.

Therefore, it is strongly recommended that wildlife movement measures be implemented to ensure connectivity between forest fragments within Brisbane. Specifically, such solutions should be tailored toward improving gap permeability along individual roads. For example, vegetation structure and complexity alongside smaller roads should be maintained and enhanced where necessary through the provision of a dense understory to promote richness crossing of small forest dependent species while simultaneously reducing competition and predation from larger birds (Desrochers and Hannon, 1997; Ford et al., 2000; Kutt and Woinarski, 2007; Tremblay and St Clair, 2009; Jones and Bond, 2010; Jones et al., 2011; Thinh et al., 2012). However, it should be noted that encouraging species to cross roads may in turn expose them to greater risk of mortality, the implications of which become far greater in instances when rare species are involved (Jaeger and Fahrig, 2004). Alternatively, serious consideration should be given to the implementation of vegetated wildlife overpasses over larger roads and motorways. Although costly, this method has previously proven to be highly successful in promoting the movements of several species and has additional mitigation value for multiple taxa beyond birds (Jones and Bond, 2010; Jones et al., 2011; Jones, 2014; Pell and Jones, 2015). Thus, the cost may be high and perhaps unjustifiable for birds alone, but where vegetated overpasses are built for multiple species, benefits can accrue for birds if design objectives include bird passage. 
Further studies should also be undertaken of the impacts of gaps in vegetation continuity not associated with vehicular activity (i.e., forest tracks, park walkways) on bird movements, the relationship between traffic volume and species riskavoidance strategies, and the impacts of roads on the genetic and ecosystem levels, so as to better inform future planning and species conservation. This is especially important in the face of continued urbanization contributing to rapid habitat fragmentation and species displacement around the world.

\section{AUTHOR CONTRIBUTIONS}

Conceived the experiments: CJ, DE, and DJ. Performed the experiments: CJ. Analysed the data: CJ. Contributed materials/critique/analysis tools: CJ, DE, and DJ. Wrote the paper: CJ.

\section{REFERENCES}

Amos, J., Harrison, K., Radford, J., White, M., Newell, G., Nally, R., et al. (2014). Species- and sex-specific connectivity effects of habitat fragmentation in a suite of woodland birds. Ecology 95, 1556-1568. doi: 10.1890/13-1328.1

Anderson, S. (2003). The relative importance of birds and insects as pollinators of the New Zealand flora. N. Z. J. Ecol. 27, 83-94. Available online at: http://www. jstor.org/stable/24055333

Australian National Botanic Gardens. (2014). A Simplified Look at Australia's Vegetation. Available online at: https://www.anbg.gov.au/aust-veg/veg-map. html (Accessed October 22, 2015).

Benitez-Lopez, A., Alkemade, R., and Verweij, P. (2010). The impacts of roads and other infrastructure on mammal and bird populations: a meta-analysis. Biol. Conserv. 143, 1307-1316. doi: 10.1016/j.biocon.2010.02.009

Campbell, N., Reece, J. B., Myers, N., Urry, L. A., Cain, M. L., Wasserman, S. A., et al. (2010). Biology, 8th Edn. Ch. 54. Sydney: Pearson Education Inc. 1239-1240.

Desrochers, A., and Hannon, S. (1997). Gap crossing decisions by forest songbirds during the post-fledging period. Conserv. Biol. 11, 1204-1210. doi: 10.1046/j.1523-1739.1997.96187.x

Erickson, W., Johnson, G., and Young, D. Jr. (2005). A Summary and Comparison of Bird Mortality from Anthropogenic Causes with an Emphasis on Collisions. Technical Report PSW-GTR-191. USDA Forest Service Gen 1029-1042.

Evans, D. (2014). Biodiversity of a Peri-Urban Catchment. Bulimba Creek, QLD.

Ford, H., Barrett, G., Saunders, D., and Recher, H. (2000). Why have birds in the woodlands of Southern Australia declined?. Biol. Conserv. 97, 71-88. doi: 10.1016/S0006-3207(00)00101-4

Forman, R., Sperling, D., Bissonette, J. A., Clevenger, A. P., Cutshall, C. D., and Dale, V. H. (2003). Road Ecology: Science and Solutions. Washington, DC: Island Press.

Francis, C. D., Ortega, C. P., and Cruz, A. (2011). Noise pollution filters bird communities based on vocal frequency. PLoS ONE 6:e27052. doi: 10.1371/journal.pone.0027052

Gleeson, J., and Gleeson, D. (2012). Reducing the Impacts of Development on Wildlife. Collingwood, VIC: CSIRO Publishing.

Goodwin, S. E., and Shriver, W. G. (2010). Effects of traffic noise on occupancy patterns of forest birds. Conserv. Biol. 25, 406-411. doi: 10.1111/j.1523-1739.2010.01602.x

Goosem, M., and Marsh, H. (1997). Fragmentation of a small community by a powerline corridor through tropical rainforest. Wildl. Res. 24, 613-629. doi: 10.1071/WR96063

Grarock, K., Tidemann, C., Wood, J., and Lindenmayer, D. (2014). Are invasive species drivers of native species decline or passengers of habitat modification? A case study of the impact of the common myna (Acridotheres tristis) on Australian bird species. Austral. Ecol. 39, 106-114. doi: 10.1111/aec.12049

\section{ACKNOWLEDGMENTS}

Special thanks go to Michael Scott O'Keefe, Greg Nye (the bird guy) and James McBroom for their valuable insight and contributions toward study design, data analysis and comments. Thank you also to Transurban for permitting access to two busy motorway sites: Gateway Motorway Extension and Logan Motorway. Finally, I am grateful to two academic reviewers whose valuable comments helped improve the quality of this manuscript.

\section{SUPPLEMENTARY MATERIAL}

The Supplementary Material for this article can be found online at: http://journal.frontiersin.org/article/10.3389/fevo. 2017.00036/full\#supplementary-material

Griffioen, P. A., and Clarke M. F. (2002). Large-scale bird-movement patterns evident in eastern Australian atlas data. Emu 102, 99-125. doi: 10.1071/MU01024

Jack, J., Rytwinski, T., Fahrig, L., and Francis, C. (2015). Influence of traffic mortality on forest bird abundance. Biodivers. Conserv. 24, 1507-1529. doi: 10.1007/s10531-015-0873-0

Jacobson, S., Bliss-Ketchum, L., de Rivera, C., and Smith, W. (2016). A behaviourbased framework for assessing barrier effects to wildlife from vehicle traffic volume. Ecosphere Concepts Theory 7:e1345. doi: 10.1002/ecs2.1345

Jaeger, J. A. G., and Fahrig, L. (2004). Effects of road fencing on population persistence. Conserv. Biol. 18, pp. 1651-1657. doi: 10.1111/j.1523-1739.2004. 00304.x

Jones, D. (2014). Fauna overpasses increase habitat connectivity and road permeability. Austral. Wildl. Manage. Newsl. 26, 5-7.

Jones, D., Bakker, M., Bichet, O., Coutts, R., and Wearing, T. (2011). Restoring habitat connectivity over the road: vegetation on a fauna land-bridge in south-east Queensland. Ecol. Manage. Restor. 12, 76-79. doi: 10.1111/j.1442-8903.2011.00574.x

Jones, D., and Bond, A. (2010). Road barrier effect on small birds removed by vegetated overpass in South East Queensland. Ecol. Manage. Restor 11, 65-67. doi: 10.1111/j.1442-8903.2010.00516.x

Jones, D., Griffiths, M., Griffiths, J., Hacker, J., and Hacker, J. (2014). Implications of upgrading a minor forest road on traffic and road-kill in southeast Queensland. Austral. J. Environ. Manage. 21, 429-440. doi: 10.1080/14486563.2014.944590

Jones, D., and Pickvance, J. (2013). Forest birds use vegetated fauna overpass to cross multilane road. Oecol. Austral. 17, 42-51. doi: 10.4257/oeco.2013.1701.12

Keast, A. (1996). Wing shape in insectivorous passerines inhabiting New Guinea and Australian rainforests and eucalypt forest/eucalypt woodland. Auk 113, 94-104.

Kociolek, A., Clevenger, C., St Clair, C., and Proppe, D. (2011). Effects of road networks on bird populations. Conserv. Biol. 25, 241-249. doi: 10.1111/j.1523-1739.2010.01635.x

Kociolek, A., Grilo, C., and Jacobson, S. (2015). Flight Doesn't Solve Everything: Mitigation of Road Impacts on Birds. Handbook of Road Ecology, 1st Edn. Chichester: John Wiley \& Sons.

Kutt, A. S., and Martin, T. G. (2010). Bird foraging height predicts bird species response to woody vegetation change. Biodivers. Conserv. 19, 2247-2262. doi: 10.1007/s10531-010-9840-y

Kutt, A. S., Vanderduys, E. P., Perry, J. J., and Perkins, G. C. (2011). Do miners (Manorina spp.) affect bird assemblages in continuous savanna woodlands in north-eastern Australia?. Aust. Ecol. 37, 779-788. doi: 10.1111/j.1442-9993.2011.02338.x

Kutt, A. S., and Woinarski, J. (2007). The effects of grazing and fire on vegetation and the vertebrate assemblage in a tropical savanna woodland in north-eastern Australia. J. Trop. Ecol. 23, 95-106. doi: 10.1017/S0266467406003579 
Laurance, W. (2015). Bad Roads, Good Roads. Handbook of Road Ecology, 1st Edn. Chichester: John Wiley \& Sons.

Lees, A., and Peres, C. (2009). Gap-crossing movements predict species occupancy in Amazonian forest fragments. Oikos 118, 280-290. doi: 10.1111/j.1600-0706. 2008.16842.x

Montague-Drake, R., David, B. L., Ross, B. C., and John A. S. (2011). A reverse keystone species affects the landscape distribution of woodland avifauna: a case study using the Noisy Miner (Manorina melanocephala) and other Australian birds. Landsc. Ecol. 26, 1383-1394. doi: 10.1007/s10980-011-9665-4

Morcombe, M. (2004). Field Guide to Australian Birds. Compact Edition. Archerfield, QLD: Steve Parish Publishing.

Morelli, F., Beim, M., Jerzak, L., Jones, D., and Tryjanowski, P. (2014). Can roads, railways and related structures have positive effects on birds?. Transport. Res. D Trans. Environ. 30, 21-31. doi: 10.1016/j.trd.2014. 05.006

Norberg, U. M. (1989). Vertebtrate Flight. New York, NY: Springer-Verlag.

Oldland, J., Taylor, R., and Clarke, M. (2009). Habitat preferences of the Noisy Miner (Manorina melanocephala)-a propensity for prime real estate?. Aust. Ecol. 34, 306-316. doi: 10.1111/j.1442-9993.2009.01931.x

Orlowski, G. (2008). Roadside hedgerows and trees as factors increasing road mortality of birds: implications for management of roadside vegetation in rural landscapes. Landsc. Urban Plann. 86, 153-161. doi: 10.1016/j.landurbplan.2008.02.003

Palomino, D., and Carrascal, L. (2007). Threshold distances to nearby cities and roads influence the bird community of a mosaic landscape. Biol. Conserv. 140, 100-109. doi: 10.1016/j.biocon.2007.07.029

Pell, S., and Jones, D. (2015). Are wildlife overpasses of conservation value for birds? A study in Australian sub-tropical forest, with wider implications. Biol. Conserv. 184, 300-309. doi: 10.1016/j.biocon.2015.02.005

Philpott, S., Soong, O., Lowenstein, J., Pulido, A., Lopez, D., Flynn, D., et al. (2009). Functional richness and ecosystem services: bird predation on arthropods in tropical agroecosystems. Ecol. Appl. 19, 1858-1867. doi: 10.1890/08-1928.1

Read, J., Parkhurst, B., and Delean, S. (2015). Can Australian bush birds be used as canaries? Detection of pervasive environmental impacts at an arid Australian mine site. Emu 115, 117-125. doi: 10.1071/MU14069

Reijnen, R., and Foppen, R. (2006). Impact of road traffic on breeding bird populations. Ecol. Transp. 12, 255-274. doi: 10.1007/1-4020-4504-2_12

Reside, A. E., VanDerWal, J. J., Kutt, A. S., and Perkins, G. C. (2010). Weather, not climate, defines distributions of vagile bird species. PLOS ONE 5:e13569. doi: 10.1371/journal.pone.0013569

Rheindt, F. E. (2003). The impact of roads on birds: does song frequency play a role in determining susceptibility to noise pollution?. J. Ornithol. 144, 295-306. doi: $10.1007 / \mathrm{BF} 02465629$

Roberts, K., and Sjolund, A. (2015). Incorporating Biodiversity Issues into Road Design: The Road Agency Perspective. Handbook of Road Ecology, 1st Edn. Chichester: John Wiley \& Sons
Rytwinski, T., and Fahrig, L. (2012). Do species life history traits explain population responses to roads? A Meta-analysis. Biol. Conserv. 147, 87-98. doi: 10.1016/j.biocon.2011.11.023

Selva, N., Switalski, A., Kreft, S., and Ibisch, P. (2015). Why Keep Areas Road Free? The Importance of Roadless Areas. Handbook of Road Ecology, 1st Edn. West Sussex: John Wiley \& Sons.

Specht, R. L. (1970). Vegetation. Pages $44-67$ in Leeper G.W. Australian Environment, 4th Edn. Melbourne, VIC: Melbourne University Press.

St Claire, C. (2003). Comparative permeability of roads, rivers, and meadows to songbirds in banff national park. Conserv. Biol. 17, 1151-1160. doi: 10.1046/j.1523-1739.2003.02156.x

Summers, P., Cunnington, G., and Fahrig, L. (2011). Are the negative effects of roads on breeding birds caused by traffic noise?. J. Appl. Ecol. 48, 1527-1534. doi: 10.1111/j.1365-2664.2011.02041.x

Thinh, V., Doherty, P., Bui, T., and Huyvaert, K. (2012). Road crossing by birds in a tropical forest in northern Vietnam. Condor 114, 639-644. doi: 10.1525/cond.2012.100199

Tremblay, M., and St Clair, C. (2009). Factors affecting the permeability of transportation and riparian corridors to the movements of songbirds in an urban landscape. J. Appl. Ecol. 46, 1314-1322. doi: 10.1111/j.1365-2664.2009.01717.x

Van der Ree, R., Smith, D., and Grilo, C. (2015). The Ecological Effects of Linear Infrastructure and Traffic: Challenges and Opportunities of Rapid Global Growth. Handbook of Road Ecology, 1st Edn. Chichester: John Wiley \& Sons.

Wenny, D., Devault, T., Johnson, M., Kelly, D., Sekercioglu, C., Tomback, D., et al. (2011). Perspectives in Ornithology: the need to quantify ecosystem services provided by birds. Auk 128, 1-14. doi: 10.1525/auk.2011.10248

Whelen, C., Wenny, D., and Marquis, R. (2008). Ecosystem services provided by birds. Ann. N. Y. Acad. Sci. 1134, 25-60. doi: 10.1196/annals.1439.003

Zhang, S., Suo, M., Liu, S., and Liang, W. (2013). Do major roads reduce gene flow in urban bird populations?. PLoS ONE 8:e77026. doi: 10.1371/journal.pone.0077026

Zimmer, C., and Emlen, D. (2013). Evolution: Making Sense of Life. Greenwood Village, CO: Roberts and Company Publishers.

Conflict of Interest Statement: The authors declare that the research was conducted in the absence of any commercial or financial relationships that could be construed as a potential conflict of interest.

Copyright $(\odot) 2017$ Johnson, Evans and Jones. This is an open-access article distributed under the terms of the Creative Commons Attribution License (CC BY). The use, distribution or reproduction in other forums is permitted, provided the original author(s) or licensor are credited and that the original publication in this journal is cited, in accordance with accepted academic practice. No use, distribution or reproduction is permitted which does not comply with these terms. 